\title{
Effect of pelvic drain displacement on anastomotic leakage-related morbidity after rectal cancer surgery
}

\author{
Ho Yung Lee, Sung II Kang, So Hyun Kim, Jae-Hwang Kim \\ Department of Surgery, Yeungnam University Medical Center, Yeungnam University College of Medicine, Daegu, Korea
}

Purpose: Drain insertion after proctectomy is common in clinical practice, although the effectiveness of drains has been questioned. However, drains are commonly displaced after surgery. We hypothesized that drain displacement is associated with clinical outcomes and aimed to assess differences in clinical outcomes, such as overall morbidity, including anastomotic leakage $(\mathrm{AL})$, reintervention rates, length of hospital stay, and mortality rates, between patients who experienced displaced drains and those who did not.

Methods: Rectal cancer patients who underwent proctectomy at a single institution between January 2015 and December 2020 were retrospectively reviewed. Clinical characteristics were compared between patients who experienced displaced drains and those who did not. The primary endpoint was the occurrence of reintervention in patients with AL. The secondary endpoints were overall morbidity rates, AL rates, length of hospital stay, and mortality within 30 days.

Results: Among 248 patients who underwent proctectomy, 93 (37.5\%) experienced displaced drains. A higher proportion of patients who experienced displaced drains required reintervention due to AL than those who did not experience displaced drains (odds ratio, 3.61; 95\% confidential interval, 1.20-10.93; $p=$ 0.016). However, no significant difference was found in the overall morbidity rate, mortality, and length of hospital stay between the groups.

Conclusion: Drain displacement does not worsen outcomes such as overall morbidity rate, mortality, and length of hospital stay after proctectomy but is associated with an increase in the need for reintervention in patients with AL.

Keywords: Proctectomy, Drainage, Rectal neoplasms, Anastomotic leak

This is an Open Access article distributed under the terms of the Creative Commons Attribution Non-Commercial License (http:// creativecommons.org/licenses/by-nc/4.0/) which permits unrestricted non-commercial use, distribution, and reproduction in any medium, provided the original work is properly cited.
Received June 30,2021

Revised August 28, 2021

Accepted September 4, 2021

Corresponding author

Sung Il Kang

Department of Surgery, Yeungnam

University Medical Center, 170

Hyeonchung-ro, Nam-gu, Daegu

42415, Korea

Tel: $+82-53-620-3580$

Fax: +82-31-787-4055

E-mail: sungiry@naver.com

ORCID:

https://orcid.org/0000-0002-4751-5779
Copyright (C) The Korean Society of Endoscopic and Laparoscopic Surgeons.

\section{INTRODUCTION}

Anastomotic leakage (AL) is a serious complication that can occur after rectal cancer surgery. The rate of clinically significant AL may be as high as $20 \%[1,2]$ and results in longer hospital stays and higher mortality rates. Early detection and treatment of $\mathrm{AL}$ after surgery is thus important for favorable clinical outcome of rectal cancer surgery patients.

AL can be diagnosed using radiologic studies, laboratory findings, and/or physical examinations. Symptomatic AL is diagnosed when there are clinical symptoms, such as fever and abdominal pain, and when gas, feces, or pus emerges from the drain.

Antibiotics and drainage of the reactive fluid are needed for the treatment of AL after proctectomy. Reoperation may also be required to treat pelvic sepsis caused by AL. Early detection and treatment of AL are particularly important after proctectomy [3-5]. 
Surgeons have traditionally used drain insertion after bowel surgery for the early detection of AL and removal of the infection source. Numerous studies have explored the clinical association between drain insertion and reduction of subsequent surgical complications such as AL and pelvic sepsis. Most studies concluded that the benefits associated with drain insertion are limited [6-10]. Despite this, drain insertion after bowel surgery is widely used in practice.

Few studies, however, have considered the displacement of the drain as a variable affecting clinical outcome. The drain sometimes moves from its original placement due to the patient's position change and gut peristaltic movement [10]. Displacement of the drain is associated with ineffective drainage of the infection source, which could explain the limited benefit of drain insertion reported in recent studies.

This study aimed to assess differences in clinical outcomes, such as the incidence of $\mathrm{AL}$, reintervention rate, length of hospital stay, and mortality, between patients who experienced drain displacement and those in whom the drain remained unmoved after placement.

\section{MATERIALS AND METHODS}

\section{Patients}

This study included 248 rectal cancer patients who underwent low anterior resection (LAR) at the department of colorectal surgery in Yeungnam University Medical Center (Daegu, Korea) between January 2015 and December 2020. We selected all patients over 20 years of age who had LAR, regardless of preoperative chemoradiotherapy, clinical stage, or fecal diversion such as a protective stoma. Patients who underwent emergency surgery, additional colonic resection and anastomosis due to synchronous colon cancer, abdominoperineal resection, or Hartman operation were excluded. The study flowchart is shown in Fig. 1.

\section{Surgery}

Surgeries were performed using open, laparoscopic, or robotic techniques by four surgeons who specialized in colorectal cancer surgery. For most patients, preoperative bowel preparation was achieved unless the patient had a bowel obstruction. The surgical procedure was standardized radical surgery for malignant colorectal cancer. Colorectal or coloanal anastomosis was performed using the conventional double stapling technique or hand-sewn technique for a few of the patients who needed coloanal anastomosis. Temporary fecal diversion was used for low rectal cancer or if directed by the surgeon. At the end of the procedure, a drain was inserted into the pelvic cavity using a trocar port or small incision, with the tip of the drain placed near the anastomosis line. The type of drain was a negative-pressure silicon drain. The drain was removed either on the 7th day after surgery or 1 day prior to discharge, provided there were no specific problems after dietary progression or once the hole of drain had clotted.

\section{Definition of drain displacement}

We defined drain displacement as when the tip of the drain migrated outside of the pelvic inlet or when the nearest surface of the drain was more than $5 \mathrm{~cm}$ away from the anastomosis stapler line in the radiologic study (Fig. 2).

Routine simple abdominal radiography was performed 2, 4, and 6 days after the operation, with additional radiography being performed as required for clinical examination. Abdominal computed tomography (CT) was performed when directed by the surgeon or if there was a clinical symptom.

\section{Definition of anastomotic leakage}

Clinically, AL was diagnosed when gas, pus, or fecal material emerged through the drain, wound, or vagina, or when anastomotic disruption was detected by digital rectal examination, endoscopy, or barium enema. Patients who had fever and leuko-

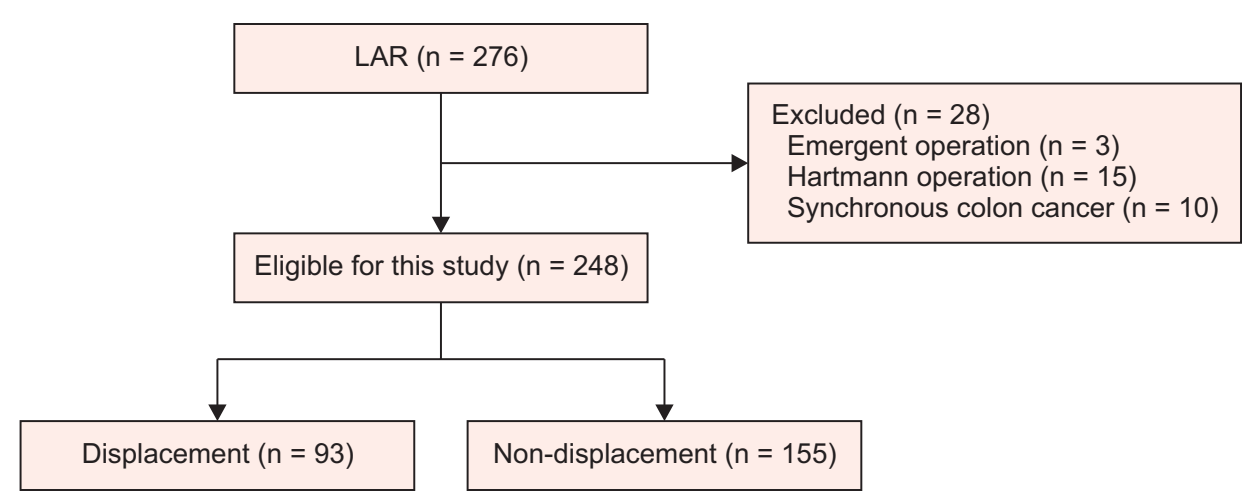

Fig. 1. Study flowchart. LAR, low anterior resection. 
cytosis with anastomotic site fluid collection in the CT scan were also diagnosed with AL.

The severity of AL was graded according to the definitions proposed by Rahbari et al. [11]. Grade A AL requires no change in patient management. Grade B AL is manageable without reoperation and can be treated with active therapeutic intervention, including radiologic intervention and medical therapy. Grade $\mathrm{C}$ $\mathrm{AL}$ requires reoperation.

\section{Endpoint}

The primary endpoint of this study was the occurrence of reintervention, such as percutaneous drainage or reoperation in patients with AL. The secondary endpoints were overall morbidity rates as defined by Dindo et al. [12], AL rates, length of hospital stay, and mortality within 30 days.

\section{Statistical analysis}

All statistical analyses were performed using IBM SPSS version 22.0. (IBM Corp. Armonk, NY, USA). Quantitative variables were compared with Student $t$ tests and qualitative variables were compared with chi-square tests or Fisher exact tests. A $p$ value of $<0.05$ was considered to indicate statistical significance. Binary logistic regression was used in univariate analysis.

\section{RESULTS}

Patient characteristics are listed in Table 1. A displaced drain occurred in 93 patients (37.5\%) of the 248 patients, and drain displacement most frequently occurred on the second day after surgery (Table 2).

Postoperative clinical outcomes are summarized in Table 3. Grade B or higher AL occurred in 20 patients (21.5\%) who experienced a displaced drain and 27 patients (17.4\%) in whom the drain
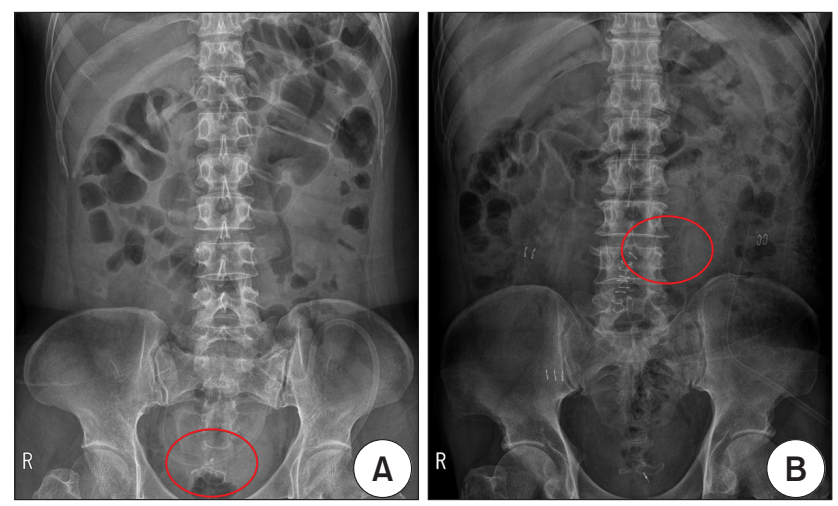

Fig. 2. Abdominal radiograph after surgery. (A) An example of a nondisplaced drain and (B) a displaced drain. was not displaced. There was no significant difference between these proportions $(p=0.427)$. Among the patients who developed $\mathrm{AL}$, reintervention, including percutaneous drainage, or reoperation were performed significantly more frequently $(p=0.016)$ for patients who experienced a displaced drain (10 of $93,10.8 \%)$ than for patients in whom the drain was not displaced (5 of 155, 3.2\%) (Table 4). Morbidity of Clavien-Dindo grade I or higher and the average length of hospital stay were not significantly different between patients who experienced a displaced drain and those who did not ( $p=0.815$ and $p=0.939$, respectively). There was only one mortality within 30 days. This was a patient in whom

Table 1. Patient's characteristics

\begin{tabular}{|c|c|c|c|}
\hline Characteristic & Displacement & $\begin{array}{c}\text { Non- } \\
\text { displacement }\end{array}$ & $p$ value \\
\hline No. of patients & 93 & 155 & \\
\hline Age (yr) & $65.10 \pm 11.05$ & $65.59 \pm 11.59$ & 0.162 \\
\hline Sex & & & 0.426 \\
\hline Male & $59(63.4)$ & $106(68.4)$ & \\
\hline Female & $34(36.6)$ & $49(31.6)$ & \\
\hline Body mass index $\left(\mathrm{kg} / \mathrm{m}^{2}\right)$ & $22.88 \pm 3.01$ & $24.09 \pm 3.41$ & 0.414 \\
\hline ASA PS classification & & & 0.174 \\
\hline $\mid-\|$ & $84(90.3)$ & $147(94.8)$ & \\
\hline$\|||-\mid V$ & $9(9.7)$ & $8(5.2)$ & \\
\hline Tumor size, mm & $45.82 \pm 3.15$ & $44.07 \pm 3.31$ & 0.591 \\
\hline \multicolumn{2}{|c|}{ Preoperative chemoradiotherapy } & & $>0.999$ \\
\hline Yes & $18(19.4)$ & $30(19.4)$ & \\
\hline No & $75(80.6)$ & $125(80.6)$ & \\
\hline Surgical approach & & & 0.294 \\
\hline Open & $10(10.8)$ & $24(15.5)$ & \\
\hline $\begin{array}{l}\text { Laparoscopy } \\
\text { (including robot) }\end{array}$ & 83 (89.2) & $131(84.5)$ & \\
\hline Operation time (min) & $204.13 \pm 63.99$ & $217.16 \pm 74.02$ & 0.543 \\
\hline Fecal diversion & & & 0.464 \\
\hline Yes & $65(69.9)$ & $115(74.2)$ & \\
\hline No & $28(30.1)$ & $40(25.8)$ & \\
\hline Anastomotic height (cm) & $5.39 \pm 2.09$ & $5.45 \pm 1.95$ & 0.389 \\
\hline TNM stage & & & 0.443 \\
\hline $0-\|$ & $46(49.5)$ & 64 (41.3) & \\
\hline III & $36(38.7)$ & $68(43.9)$ & \\
\hline IV & $11(11.8)$ & $23(14.8)$ & \\
\hline
\end{tabular}

Values are presented as number only, mean \pm standard deviation, or number (\%).

ASA, American Society Anesthesiologists; PS, physical status. 
Table 2. Date of drain displacement

\begin{tabular}{cc}
\hline Day & Displacement $(\mathrm{n}=93)$ \\
\hline 1 & $2(2.2)$ \\
\hline 2 & $30(32.3)$ \\
\hline 3 & $21(22.6)$ \\
\hline 4 & $16(17.2)$ \\
\hline 5 & $11(11.8)$ \\
\hline 6 & $2(2.2)$ \\
\hline 7 & $11(11.8)$ \\
\hline
\end{tabular}

Values are presented as number (\%).

Table 3. Clinical outcome after surgery

\begin{tabular}{lccc}
\hline \multicolumn{1}{|c}{ Variable } & $\begin{array}{c}\text { Displacement } \\
(\mathrm{n}=93)\end{array}$ & $\begin{array}{c}\text { Non- } \\
\text { displacement } \\
(\mathrm{n}=155)\end{array}$ & $p$ value \\
\hline Morbidity & $38(40.9)$ & $61(39.4)$ & 0.815 \\
\hline Anastomotic leakage & $20(21.5)$ & $27(17.4)$ & 0.427 \\
\hline 30-day mortality & $0(0)$ & $1(0.6)$ & 0.438 \\
\hline Hospital stay (day) & $11.11 \pm 6.47$ & $10.84 \pm 6.46$ & 0.939 \\
\hline
\end{tabular}

Values are presented as number (\%) or mean \pm standard deviation.

Table 4. Reintervention after surgery

\begin{tabular}{lccc}
\multicolumn{1}{c}{ Variable } & $\begin{array}{c}\text { Non- } \\
(\mathrm{n}=93)\end{array}$ & $\begin{array}{c}\text { Nonement } \\
\text { displace- } \\
\text { ment }\end{array}$ & $p$ value \\
& & $(\mathrm{n}=155)$ & \\
\hline Reintervention & $10(10.8)$ & $5(3.2)$ & 0.016 \\
Percutaneous drainage & $2(2.2)$ & $1(0.6)$ & 0.294 \\
Reoperation & $8(8.6)$ & $4(2.6)$ & 0.032
\end{tabular}

the drain was not displaced, and the cause of death was sudden cardiac arrest likely to have been caused by acute myocardial infarction. The predictive variables for AL are presented in Table 5. Patients who underwent preoperative chemoradiotherapy had a significantly higher incidence of AL (odds ratio [OR], 2.47; 95\% confidence interval [CI], 1.11-5.50; $p=0.026$ ).

The predictive variables for reintervention in patients with AL are listed in Table 6. The incidence of reintervention was significantly higher in patients who experienced a displaced drain (OR, 3.61; 95\% CI, 1.20-10.93; $p=0.016)$ and significantly lower in patients aged $>65$ years (OR, $0.14 ; 95 \%$ CI, $0.30-0.61 ; p=0.003$ ).
Table 5. Predictive variables of anastomotic leakage

\begin{tabular}{|c|c|c|c|}
\hline \multirow{2}{*}{ Variable } & \multicolumn{3}{|c|}{ Anastomotic leakage } \\
\hline & №. (\%) & OR (95\% Cl) & $p$ value \\
\hline \multicolumn{4}{|l|}{ Sex } \\
\hline Male & $34(20.6)$ & $1.51(0.71-3.21)$ & \\
\hline Female & $13(15.7)$ & 1.00 & 0.282 \\
\hline \multicolumn{4}{|l|}{ Age (yr) } \\
\hline$\leq 65$ & $22(17.5)$ & 1.00 & \\
\hline$>65$ & $25(20.5)$ & $0.96(0.48-1.93)$ & 0.916 \\
\hline \multicolumn{4}{|c|}{ Body mass index $\left(\mathrm{kg} / \mathrm{m}^{2}\right)$} \\
\hline$\leq 25$ & $34(20.6)$ & 1.00 & \\
\hline$>25$ & $13(15.7)$ & $0.67(0.32-1.41)$ & 0.296 \\
\hline \multicolumn{4}{|c|}{ ASA PS classification } \\
\hline $\mid-\|$ & $42(18.2)$ & 1.00 & \\
\hline III-IV & $5(29.4)$ & $1.73(0.54-5.57)$ & 0.361 \\
\hline \multicolumn{4}{|l|}{ PCRT } \\
\hline No & $31(15.5)$ & 1.00 & \\
\hline Yes & $16(33.3)$ & $2.47(1.11-5.50)$ & 0.026 \\
\hline \multicolumn{4}{|c|}{ Anastomotic height (cm) } \\
\hline$\leq 5$ & 28 (23.3) & 1.00 & \\
\hline$>5$ & $19(14.8)$ & $0.64(0.30-1.33)$ & 0.231 \\
\hline \multicolumn{4}{|l|}{ Fecal diversion } \\
\hline No & $10(14.7)$ & 1.00 & \\
\hline Yes & 37 (20.6) & $0.92(0.38-2.25)$ & 0.862 \\
\hline \multicolumn{4}{|l|}{ Tumor size (mm) } \\
\hline$\leq 45$ & $33(22.0)$ & 1.00 & \\
\hline$>45$ & $14(14.3)$ & $0.68(0.33-1.40)$ & 0.294 \\
\hline \multicolumn{4}{|c|}{ Drain displacement } \\
\hline No & $27(17.4)$ & 1.00 & \\
\hline Yes & $20(21.5)$ & 1.23 (0.62-2.42) & 0.556 \\
\hline
\end{tabular}

$\mathrm{OR}$, odds ratio; $\mathrm{Cl}$, confidence interval; $\mathrm{ASA}$, American Society Anesthesiologists; PS, physical status; PCRT, preoperative chemoradiotherapy.

\section{DISCUSSION}

To the best of our knowledge, this is the first study to assess the effect of pelvic drain displacement after rectal cancer surgery on the clinical outcomes of patients. Our results demonstrate that a higher proportion of patients who experienced a displaced drain required reintervention due to AL compared to patients in whom the drain was not displaced. We, therefore, concluded that drain insertion is not a worthless procedure, considering the risks and benefits; however, it is important to determine a way to prevent 
Table 6. Predictive variables of reintervention in patients with anastomotic leakage

\begin{tabular}{|c|c|c|c|}
\hline \multirow{2}{*}{ Variable } & \multicolumn{2}{|c|}{ Reintervention } & \multirow{2}{*}{$p$ value } \\
\hline & №. $(\%)$ & OR $(95 \% \mathrm{Cl})$ & \\
\hline \multicolumn{4}{|l|}{ Sex } \\
\hline Male & $11(6.7)$ & $1.49(0.44-4.57)$ & \\
\hline Female & $4(4.8)$ & 1.00 & 0.565 \\
\hline \multicolumn{4}{|l|}{ Age (yr) } \\
\hline$\leq 65$ & $13(10.7)$ & 1.00 & \\
\hline$>65$ & $2(1.6)$ & $0.14(0.30-0.61)$ & 0.003 \\
\hline \multicolumn{4}{|c|}{ Body mass index (kg/m²) } \\
\hline$\leq 25$ & $11(6.7)$ & 1.00 & \\
\hline$>25$ & $4(4.8)$ & $0.71(0.22-2.30)$ & 0.565 \\
\hline \multicolumn{4}{|c|}{ ASA PS classification } \\
\hline $\mid-\|$ & $14(6.1)$ & 1.00 & \\
\hline$\| 11-I V$ & $1(5.9)$ & $0.97(0.12-7.84)$ & 0.976 \\
\hline \multicolumn{4}{|l|}{ PCRT } \\
\hline No & $11(5.5)$ & 1.00 & \\
\hline Yes & $4(8.3)$ & $1.56(0.48-5.14)$ & 0.460 \\
\hline \multicolumn{4}{|c|}{ Anastomotic height (cm) } \\
\hline$\leq 5$ & $9(7.5)$ & 1.00 & \\
\hline$>5$ & $6(4.7)$ & $0.61(0.21-1.76)$ & 0.353 \\
\hline \multicolumn{4}{|l|}{ Fecal diversion } \\
\hline No & $4(5.9)$ & 1.00 & \\
\hline Yes & $11(6.1)$ & $1.04(0.32-3.39)$ & 0.946 \\
\hline \multicolumn{4}{|l|}{ Tumor size (mm) } \\
\hline$\leq 45$ & $10(6.7)$ & 1.00 & \\
\hline$>45$ & $5(5.1)$ & $0.75(0.25-2.27)$ & 0.610 \\
\hline \multicolumn{4}{|l|}{ Drain displacement } \\
\hline No & $5(3.2)$ & 1.00 & \\
\hline Yes & $10(10.8)$ & 3.61 (1.20-10.93) & 0.016 \\
\hline
\end{tabular}

$\mathrm{OR}$, odds ratio; $\mathrm{Cl}$, confidence interval; ASA, American Society Anesthesiologists; PS, physical status; PCRT, preoperative chemoradiotherapy.

the drain from being displaced.

As previously described, the effectiveness of drain insertion remains debatable. A recent meta-analysis showed that a pelvic drain lowered the incidence of $\mathrm{AL}$ and the rate of reintervention in extraperitoneal colorectal anastomosis [3]. In contrast, a multicenter prospective randomized controlled trial concluded that drain insertion had no benefit in the prevention of pelvic sepsis [6]. However, no previous studies have considered drain displacement as a variable affecting clinical outcome. Therefore, we focused on the effect of drain displacement on clinical outcomes, rather than on the use of drain insertion per se.

Although studies describing the rate of drain displacement are rare, Gilbert et al. [10] reported that $31.5 \%$ of patients who underwent low abdominal surgery experienced drain displacement. This is similar to our findings where the rate of drain displacement was $37.5 \%$. The reintervention rate in patients with $\mathrm{AL}$ in our study was $6 \%$, while other studies reported rates ranging from $2 \%$ to $11 \%[6,13,14]$. Reinterventions, including percutaneous drainage and reoperation, were required in a significantly higher proportion of the patients who experienced a displaced drain than in those who did not experience a displaced drain $(10.8 \%$ vs. 3.2\%). It is remarkable that the reintervention rate in patients who experienced a displaced drain was similar or higher than that reported in other studies $[6,13,14]$. Other studies $[6,10]$ have suggested that drain insertion does not reduce the frequency at which reintervention is required. Throughout our study, however, we found that if the drain was well maintained and did not get displaced, the need for reintervention could be reduced.

Except for the reintervention rate, clinical outcomes such as morbidity, AL rate, 30-day mortality, and length of hospital stay were not significantly affected by drain displacement. Despite this lack of statistical power, however, clinical outcomes in patients who experienced a displaced drain tended to be worse. Preventing reintervention is important, not only in terms of clinical outcomes but also considering the socioeconomic cost and psychological stress that the patient may experience.

It has also been argued that drain insertion may result in detrimental side effects, including wound and intra-abdominal infections, postoperative pain, increased length of stay, and altered ventilatory function due to drainage [15-19]. A small number of case studies have also reported bowel perforation due to silicon drain [20]. In our study, however, there were no remarkable drain-related complications except for one case of an infection of the drain insertion site wound. We believe that the benefit of preventing the need for reintervention due to $\mathrm{AL}$ outweighs the risks of the above uncommon side effects. The drain insertion procedure is also simple; therefore, we believe that it is feasible to insert a drain during proctectomy.

There are limited studies on preventing drain displacement after proctectomy. In our center, we have been using the intraperitoneal drain fixation method using an absorbable 3-0 stitch. Among the few studies on intraperitoneal drain fixation, a retrospective study on the effectiveness of intraperitoneal drain fixation after distal pancreatectomy showed that it has a significant pancreatic fistula reduction effect [21]. Therefore, favorable results for intraperitoneal drain fixation after rectal surgery are also expected; however, a follow-up study on its effectiveness is needed.

There is another debate on reduction of AL incidence in pa- 
tients with fecal diversion. Previous studies have reported that temporary ileostomy can reduce AL [2,4]. However, other studies have reported that there is no statistically significant association between AL and fecal diversion [5,6,13]. In our study, fecal diversion did not influence AL, overall morbidity, 30-day mortality, length of hospital stay, and reintervention. This result was excluded from the study because it was not the result we focused on.

This study had several limitations. First, this study was a retrospective study because drain displacement, as a variable, can only be assessed after it has occurred. Second, routine abdominal radiographs were only taken 2, 4, and 6 days after surgery; therefore, the exact day on which the drain was displaced could not be determined. However, considering the risk of unnecessary radiation exposure for the patient, it is not necessary to take additional radiographs unless they are clinically required. Third, CT was not performed for all the patients. Simple abdominal radiography showed only a two-dimensional view; however, CT could help determine the location of the drain more accurately with a three-dimensional view, which was more effective for detecting drain displacement. Because CT was only performed in cases where intra-abdominal complications were suspected, such as patients with clinical symptoms, leukocytosis, or elevated Creactive protein in laboratory tests, this could have introduced an element of bias. Fourth, the incidence rate of AL in our study was higher than that reported in previous studies [1,2]. The reason for the higher AL rate in our study may be related to additional CT examinations. The other studies that included early routine evaluation of $\mathrm{AL}$, such as $\mathrm{CT}$, reported that the incidence rate of AL was $>20 \%[22,23]$. In our study, abdominal CT was performed when directed by the surgeon or if there was a clinical symptom. There were many cases in which CT was performed at the surgeon's discretion. Finally, the sample size of AL patients requiring reinterventions was small.

In conclusion, the effectiveness of drainage has been questioned; however, this study suggests that drain displacement is an important factor for patients with AL. A method to prevent displacement should be devised, and additional research is required to explore the effectiveness of pelvic drains when displacement of the drain is prevented.

\section{NOTES}

\section{Ethical statements}

This study was approved by the Institutional Review Board of Yeungnam University Medical Center (No. 2021-03-015). This study was performed in accordance with the Declaration of Helsinki. Written informed consent was waived due to its retrospective nature.

\section{Authors' Contributions}

Conceptualization: JHK, HYL

Formal analysis: HYL

Methodology: SHK, HYL

Writing-original draft: SIK, HYL

Writing-review \& editing: SIK, HYL

All authors read and approved the final manuscript.

\section{Conflict of interest}

All authors have no conflicts of interest to declare.

\section{Funding/support}

None.

\section{ORCID}

Ho Yung Lee, https://orcid.org/0000-0002-1619-7405

Sung Il Kang, https://orcid.org/0000-0002-4751-5779

So Hyun Kim, https://orcid.org/0000-0002-8625-329X

Jae-Hwang Kim, https://orcid.org/0000-0002-8556-6315

\section{REFERENCES}

1. Harris LJ, Phillips BR, Maxwell PJ, Isenberg GA, Goldstein SD. Outcomes of low anterior resection anastomotic leak after preoperative chemoradiation therapy for rectal cancer. Am Surg 2010;76:747-751.

2. Lee BC, Lim SB, Lee JL, et al. Defunctioning protective stoma can reduce the rate of anastomotic leakage after low anterior resection in rectal cancer patients. Ann Coloproctol 2020 Jan 16 [Epub]. https:// doi.org/10.3393/ac.2019.11.19.1.

3. Rondelli F, Bugiantella W, Vedovati MC, et al. To drain or not to drain extraperitoneal colorectal anastomosis? A systematic review and meta-analysis. Colorectal Dis 2014;16:O35-O42.

4. Peeters KC, Tollenaar RA, Marijnen CA, et al. Risk factors for anastomotic failure after total mesorectal excision of rectal cancer. Br J Surg 2005;92:211-216.

5. Tsujinaka S, Kawamura YJ, Konishi F, Maeda T, Mizokami K. Pelvic drainage for anterior resection revisited: use of drains in anastomotic leaks. ANZ J Surg 2008;78:461-465.

6. Denost Q, Rouanet P, Faucheron JL, et al. To Drain or not to drain infraperitoneal anastomosis after rectal excision for cancer: the GRECCAR 5 randomized trial. Ann Surg 2017;265:474-480.

7. Urbach DR, Kennedy ED, Cohen MM. Colon and rectal anastomoses do not require routine drainage: a systematic review and metaanalysis. Ann Surg 1999;229:174-180.

8. Yeh CY, Changchien CR, Wang JY, et al. Pelvic drainage and other risk factors for leakage after elective anterior resection in rectal can- 
cer patients: a prospective study of 978 patients. Ann Surg 2005;241:913.

9. Merad F, Hay JM, Fingerhut A, et al. Is prophylactic pelvic drainage useful after elective rectal or anal anastomosis? A multicenter controlled randomized trial. French Association for Surgical Research. Surgery 1999;125:529-535.

10. Gilbert A, Ortega-Deballon P, Di Giacomo G, Cheynel N, Rat P, Facy O. Intraperitoneal drains move. J Visc Surg 2018;155:105-110.

11. Rahbari NN, Weitz J, Hohenberger W, et al. Definition and grading of anastomotic leakage following anterior resection of the rectum: a proposal by the International Study Group of Rectal Cancer. Surgery 2010;147:339-351.

12. Dindo D, Demartines N, Clavien PA. Classification of surgical complications: a new proposal with evaluation in a cohort of $6336 \mathrm{pa}-$ tients and results of a survey. Ann Surg 2004;240:205-213.

13. Akiyoshi T, Ueno M, Fukunaga $\mathrm{Y}$, et al. Incidence of and risk factors for anastomotic leakage after laparoscopic anterior resection with intracorporeal rectal transection and double-stapling technique anastomosis for rectal cancer. Am J Surg 2011;202:259-264.

14. Peng J, Lu J, Xu Y, et al. Standardized pelvic drainage of anastomotic leaks following anterior resection without diversional stomas. Am J Surg 2010;199:753-758.

15. Wada S, Hatano E, Yoh T, et al. Is routine abdominal drainage necessary after liver resection? Surg Today 2017;47:712-717.
16. Zhang W, He S, Cheng Y, et al. Prophylactic abdominal drainage for pancreatic surgery. Cochrane Database Syst Rev 2018;6:CD010583.

17. Shwaartz C, Fields AC, Aalberg JJ, Divino CM. Role of drain placement in major hepatectomy: a NSQIP analysis of procedure-targeted hepatectomy cases. World J Surg 2017;41:1110-1118.

18. Wu X, Tian W, Kubilay NZ, Ren J, Li J. Is it necessary to place prophylactically an abdominal drain to prevent surgical site infection in abdominal operations? A systematic meta-review. Surg Infect (Larchmt) 2016;17:730-738.

19. Yong L, Guang B. Abdominal drainage versus no abdominal drainage for laparoscopic cholecystectomy: A systematic review with metaanalysis and trial sequential analysis. Int J Surg 2016;36(Pt A):358-368.

20. Nomura T, Shirai Y, Okamoto H, Hatakeyama K. Bowel perforation caused by silicone drains: a report of two cases. Surg Today 1998;28:940-942.

21. Sugiyama M, Suzuki Y, Abe N, et al. Secure placement of a peripancreatic drain after a distal pancreatectomy. Am J Surg 2010;199:178182.

22. Pakkastie TE, Ovaska JT, Pekkala ES, Luukkonen PE, Järvinen HJ. A randomized study of colostomies in low colorectal anastomoses. Eur J Surg 1997;163:929-933.

23. Tagart RE. Restorative rectal resection: an audit of 220 cases. Br J Surg 1986;73:70-71. 